\title{
Assessment on Management Practice and Major Health Problems of Dairy Farms in And Around Wolaita Sodo, Southern Ethiopia
}

\author{
Eyob Goa ${ }^{1}$, Endale Balcha ${ }^{1}$ and Haben Fesseha ${ }^{2 *}$ \\ ${ }^{1}$ College of Veterinary Science, Mekelle University, Ethiopia \\ ${ }^{2}$ School of Veterinary Medicine, Wolaita Sodo University, Ethiopia \\ *Corresponding author: Haben Fesseha, School of Veterinary Medicine, Wolaita Sodo University, Ethiopia
}

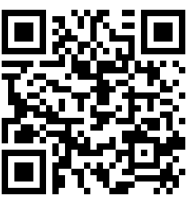

\section{ARTICLE INFO}

Received: 幽 July 30, 2020

Published: 猘 September 08, 2020

Citation: Eyob Goa, Endale Balcha, Haben Fesseha. Assessment on Management Practice and Major Health Problems of Dairy Farms in And Around Wolaita Sodo, Southern Ethiopia. Biomed J Sci \& Tech Res 30(1)-2020. BJSTR. MS.ID.004904.

Keywords: Dairy Farms; Cross-sectional; Management Practice; Major Health Problems; Wolaita Sodo

\begin{abstract}
The current cross-sectional study was conducted from November 2019 to April 2020 in and around Wolaita Sodo district to assess the management practice and major health problems of dairy cows and the awareness level of dairy farm owners and workers on good farm management practices in selected dairy farms. During the assessment, a total of 102 dairy farm owners and workers were interviewed. Accordingly, 52.94\% of respondents were male whereas $47.06 \%$ of them were females. Most farm owners had a diploma and above (32.35\%) with the experience of 5-10 years were $(40.20 \%)$. Most of the farms in the present study were small-scale $(44.12 \%)$ farms followed by mediumscale $(31.37 \%)$ and large-scale $(24.51 \%)$ farms. Although the majority of the dairy farm workers (94.12\%) use mixed feed type and (56.86\%) of respondent have awareness of the feed formulation. Animal feed shortages (41.18\%) and disease $(20.59 \%)$ were the main challenges faced by respondents hindering their sustainability. Regarding the feed and feeding of the dairy sector, feed shortage was reported as the main challenge especially in the dry season (58.82\%). During the current study major health challenges observed such as parasitic (tick infestation, 4.90\%), reproductive (Mastitis and uterine prolapse, $0.98 \%$ ), and other disorders (Hoof overgrowth, $19.60 \%$, Lameness, $0.98 \%$ and wound problem, $0.98 \%$ ). According to the response rate of interviewee vaccination, modern treatment and do nothing of affected animals were used to contain the disease as responded by $(88.24 \%, 86.27 \%$, and $11.76 \%)$ of respondents respectively. From the current study, it was concluded that the daily feed supply to animals was relatively better $(56.86 \%)$ by feed formulation but not that much satisfactory. Therefore, detailed on-farm monitoring research on the existing practice of ration formulation by the farmer to come up with possible interventions was very important.
\end{abstract}

\section{Introduction}

Globally, the livestock sector is highly dynamic and contributes $40 \%$ of the global value of agricultural output and support the livelihoods and food security of almost a billion people [1]. The Ethiopian total cattle population is estimated to be about 56.71 million. Out of this the female cattle constitute about $55.45 \%$ and the remaining $44.55 \%$ are male cattle and $98.66 \%$ of the total cattle in the country are local breeds and remaining are hybrid and exotic breeds that accounted for about $1.19 \%$ and $0.14 \%$, respectively [2]. The livestock sector plays a vital role and accounts for approximately 30\% of the total agricultural GDP and $16 \%$ of national foreign currency earrings to the Ethiopian economy $[3,4]$. In developing countries, the dairy sector has a greater potential especially in poverty alleviation by increasing the income of dairy producers (sales of milk and milk products) and improving the living standards of people, improved nutrition arising from milk consumption and creating employment and transforming the existing largely subsistent type of milk production to commercial level [5,6]. 
Ethiopia has a relatively favorable climate for a large livestock population, especially for the dairy industry. Yet, the products and productivity remained very low as compared to a huge potential resource. This is due to the impact of the disease, ectoparasite, scarcity of nutrition, inefficient and insufficient Artificial Insemination ( $\mathrm{AI})$, infectious diseases, non-infection disease, reproductive problems, poor management, lack of marketing facilities, reproductive challenges, and inadequate veterinary service. All these resulted in different direct and indirect health challenges in dairy farms [7]. The presence of these challenges results in poor health performance, low genetic potential, and the traditional way of husbandry which brings considerable economic losses to dairy farms. Among the major problems that have a direct impact on health performance of dairy cow includes, mastitis (clinical and subclinical), tick infestation, reproductive problem and poor management (feeding and housing), inadequate veterinary service, lack of accurate heat detection and insemination have contributed considerably to delay the first service, take long days to become estrous, long calving interval, short lactation length and low milk production [8].

Infectious diseases have a direct impact on the reproductive performance of dairy cows that resulted in a great economic impact on the performance of the dairy industry. They do have the potential to cause abortion, dystocia, retained placenta, pyometra, metritis, prolapse (uterine and vaginal), anoestrus, and repeat breeder. They can be classified as before gestation, during gestation, and after a gestation $[9,10]$. All these diseases are interrelated to one another and the development of the dairy industry needs comprehensive knowledge of the cause and effect of disease with its control and preventive methods [11]. There are so many dairy farms in and around Wolaita Sodo that are aimed at the provision of milk and milk products to the community. However, productivity is not as much as farmers' expectations due to different disease conditions and poor management practices. Also, that comprehensive studies made on dairy health are limited but dairy production is increasing from time to time especially in the study areas. This study is, thus, important to the area and helps to promote the desired output of dairy products and the improvement of the productivity and sustainability of the dairy sector. Therefore, the present study was designed with the objectives of assessing management practice and the major health problems of a dairy farm in and around Wolaita Sodo dairy farms.

\section{Materials and Methods}

\section{Study Area}

The study was conducted from November 2019 to April 2020 in dairy farms of Wolaita Sodo Town. Wolaita Sodo is the capital city of Wolaita zone that is situated $390 \mathrm{Km}$ south of Addis Ababa. It is situated at the latitude of $8^{\circ} 50^{\circ} \mathrm{N}$ and longitude of $37^{\circ} 45^{\circ} \mathrm{E}$ with an altitude of 2025 meters above sea level. The study area has a mean annual temperature of $20^{\circ} \mathrm{C}$ and receives a rainfall of $450-1446 \mathrm{~mm}$ [12] (Figure 1).

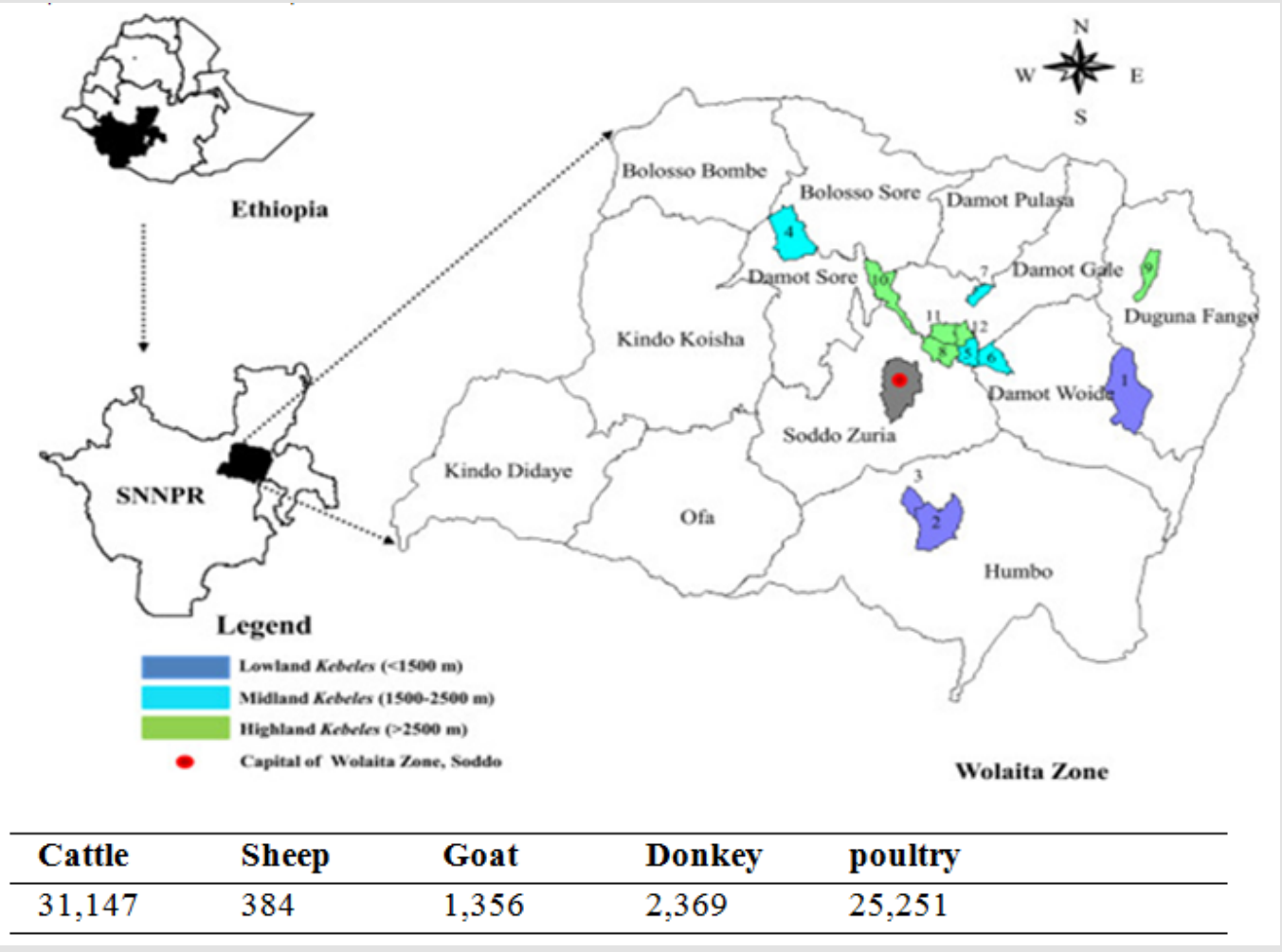

Figure 1. 


\section{Study Farms and Study Population}

The study animals of the current study were dairy cows selected from urban and peri-urban dairy farms of Wolaita Sodo. All dairy farms with at least one volunteer respondent with both sex occupation, and those which were found on a different educational level to participate in the current study were considered. Similarly, all-volunteer temporarily or permanently employed farm workers, managers, coordinators, and others related to the farm activities were included in the present study. Besides, the target dairy farms were interviewed and observed with specific questions related to assessment on management practice and major health problems in dairy farms.

\section{Study Design}

A questionnaire- and observation-based cross-sectional type of study was conducted from November 2019 to April 2020 to assess the management practice and major health problem of dairy farms for a total of six months in urban and per urban dairy farms in Wolaita Sodo. Farms were selected randomly to interviewed farm owners, and animal workers to collect the required data on management and major health problem on the dairy farm. During the study, dairy farms were categorized into small scale, medium scale and large scale dairy farms according to the number of dairy cattle that they own and dairy farms having less than 5 animals were considered as small-scale, 5-10 cattle were medium-scale and those having greater than 10 cattle were considered as large scale dairy farms [13]. The study was conducted in and around the Wolaita Sodo town and all dairy farms were purposively selected.

\section{Sample Size Determination and Sampling Technique}

The current study comprised of systematically and randomly selected dairy cow owners that are found in Sodo town and its surroundings. Thus, the required sample size for this study was estimated by considering the formula given by Arsham [59] for the questionnaire survey.

$$
\mathrm{N}=0.25 / \mathrm{SE} 2
$$

Where, $\mathrm{N}=$ sample size; $\mathrm{SE}=$ Standard error.

Accordingly, a standard error of $5 \%$ and a $95 \%$ confidence interval was considered to calculate the required sample size. Hence, a total of 102 dairy farms were selected from 180 in and around wolaita sodo registered at wolaita zone livestock and fishery resource department based on prior consent and their willingness to participate in the study. Accordingly, a total of 102 respondents consisting of farm owners, farm managers, farm attendants, permanent and temporary labor workers were sampled and assessed for their indigenous knowledge, attitude, and practices related to the husbandry and the overall management aspects of dairy farms.

The study farms were selected using a simple purposive sampling technique, and all available relevant people working in the farms were allowed to participate in the study. According to the report of the International Livestock Research Institute [13], dairy farms containing $<5$ dairy cattle were categorized as small-scale dairy farms, those with 5-10 as medium-scale farms, and farms having greater than 10 dairy cattle were categorized as large-scale dairy farms.

\section{Study Methodology and Method of Data Collection}

A questioner survey and observational types of studies were conducted for the assessment of the management practice and major health problems of dairy farms in selected dairy farms in and around Wolaita Sodo. A questionnaire was presented to each randomly selected dairy farm. The questionnaire was carried out by asking and observing dairy farms characteristics followed by specific questions related to assessment on the management and major health problems of dairy farms in selected dairy farms in study areas. A structured questionnaire was prepared to assess the management and major health problems of dairy farms in selected dairy farms in the study. The questionnaire was properly translated to the local language 'Wolaitgna' during asking and administered to the dairy farm owners, workers, managers, and veterinarians who live in and around the Wolaita Sodo town. Besides that, they were briefly told about the objective of the survey and asked for their consent before the interview was commenced.

Questionnaire Survey: A well organized, open- and closed-end questionnaire format was prepared and conducted on respondents from the selected dairy farms. Respondents were asked with several dairy farm husbandry, management, and general health-related problems including the socio-demographic distributions and characteristics of respondents, characteristic size, type, and nature of farms, feeds given and feeding protocol followed, challenges faced and others.

Observational Study: Conjointly, observational study was further conducted through regular visits to dairy farms in the study area. During each visit, regular clinical examinations of dairy cows for any sort of health problems or abnormalities. A well-designed separate format was prepared for this purpose and filled by the researcher to increase the reliability of the information collected through the questionnaire survey. On both types of study techniques, the knowledge of clinical diagnosis/history and response to treatment were the essential tools to group the diseases and problems in a systemic and comprehensive outlook.

\section{Data Management and Statistical Analysis}

All collected questionnaires and observed data were entered into the Microsoft Excel 2016 spreadsheet application program and imported to STATA version-13 statistical software for the descriptive statistical analysis, hypothesis test, and frequency percentages. Pearson's chi-square test values were used to express and compare values and correlate for any statistically significant associations between variables and factors to consider a result to be statistically significant $95 \% \mathrm{CI}$ and $\mathrm{p}$-value less than 0.05 were considered. 


\section{Results}

Socio-demographic Description of the Study Farms and

\section{Respondents}

Results of the socio-demographic survey of respondents were interviewed and the result of the questionnaire survey indicated that a majority of the respondents were male (52.94\%) compared to $(47.06 \%)$ females with different educational backgrounds and work experiences in the respective assessed dairy farms. The working experience of respondents also indicated that the majority of respondents $(40.20 \%)$ have different working experience on dairy farms ranging from 5-10. The educational background of the respondents also showed that (15.69\%, $23.53 \%, 28.43 \%$, $32.35 \%$ ) of respondents were none formal education, elementary, secondary, and diploma/above level graduates respectively (Table 1). The current study showed that the majority of visited dairy farms were $(81.37 \%)$ private-owned, (17.65\%) cooperative, and $(0.98 \%)$ government. The categorized dairy farms were small scale (44.12\%), medium-scale (31.37\%), and large scale $(24.51 \%)$. Furthermore, the majority of them (50.98\%) were closed housing types. The majority of the dairy farms of the study area were found in Sodo (84.31\%) and lesser in Sodo zuriya (15.69\%).

Table 1: Characteristic descriptions of the respondents in the dairy farms of the study area $(n=102)$.

\begin{tabular}{|c|c|c|c|}
\hline Variables & Category & Frequency (N) & Percentage (\%) \\
\hline \multirow{4}{*}{ Sex } & Male & 54 & 52.94 \\
\cline { 2 - 4 } & Female & 48 & 47.06 \\
\hline \multirow{4}{*}{$\begin{array}{c}\text { Educational } \\
\text { level }\end{array}$} & $\begin{array}{c}\text { None formal } \\
\text { education }\end{array}$ & 16 & 15.69 \\
\cline { 2 - 4 } & $\begin{array}{c}\text { Elementary } \\
\text { school }\end{array}$ & 24 & 23.53 \\
\cline { 2 - 4 } & High school & 29 & 28.43 \\
\cline { 2 - 4 } & $\begin{array}{c}\text { Diploma and } \\
\text { above }\end{array}$ & 33 & 32.35 \\
\hline \multirow{4}{*}{$\begin{array}{c}\text { Farm } \\
\text { experience (in } \\
\text { years) }\end{array}$} & 5-10 & 29 & 28.43 \\
\cline { 2 - 4 } & $>10$ & 32 & 40.20 \\
\cline { 2 - 4 } & & 41.37 \\
\hline
\end{tabular}

Out of the 102 dairy farms, $66.67 \%$ were under intensive, $32.35 \%$, semi-intensive and $0.98 \%$, extensive management systems. Furthermore, most of the dairy farms were found to keep only females (70.59\%) while both female and male were $(29.41 \%)$. Likewise, farms were seen to keep animals of different age groups with the majority of them rearing Young and adult dairy cows $(89.22 \%)$ (Table 2). The majority of dairy farm owners keeping animal breed type (92.16\%, 5.88\%, 1.96\%) were exotic, both and local respectively, additionally most of the respondent use breeding practice was $(74.51 \%)$ artificial insemination. About $20.59 \%$ of the respondents use both natural and artificial inseminations breeding system (Table 2).
Table 2: Characteristic descriptions of the study dairy farms $(n=102)$.

\begin{tabular}{|c|c|c|c|}
\hline Variables & Category & Frequency (N) & Percentage (\%) \\
\hline \multirow{3}{*}{ Farm type } & Small scale & 45 & 44.12 \\
\hline & Medium-scale & 32 & 31.37 \\
\hline & Large scale & 25 & 24.51 \\
\hline \multirow{3}{*}{$\begin{array}{l}\text { Management } \\
\text { system }\end{array}$} & Intensive & 68 & 66.67 \\
\hline & Semi intensive & 33 & 32.35 \\
\hline & Extensive & 1 & 0.98 \\
\hline \multirow{3}{*}{$\begin{array}{l}\text { Institution of } \\
\text { dairy farm }\end{array}$} & Government & 1 & 0.98 \\
\hline & Private & 83 & 81.37 \\
\hline & Cooperative & 18 & 17.65 \\
\hline \multirow{3}{*}{$\begin{array}{c}\text { Farm housing } \\
\text { type }\end{array}$} & Open-air & 48 & 47.06 \\
\hline & $\begin{array}{l}\text { Confined/ } \\
\text { closed }\end{array}$ & 52 & 50.98 \\
\hline & Both & 2 & 1.96 \\
\hline \multirow{2}{*}{$\begin{array}{c}\text { Sex of animals } \\
\text { kept }\end{array}$} & Females only & 72 & 70.59 \\
\hline & $\begin{array}{l}\text { Female and } \\
\text { Male }\end{array}$ & 30 & 29.41 \\
\hline \multirow{4}{*}{$\begin{array}{l}\text { Age class of } \\
\text { animals kept }\end{array}$} & $\begin{array}{l}\text { Young and } \\
\text { adults }\end{array}$ & 91 & 89.22 \\
\hline & Adults only & 11 & 10.78 \\
\hline & Adults and old & 0 & 0.0 \\
\hline & Old only & 0 & 0.0 \\
\hline \multirow{3}{*}{ Breed type } & Local & 2 & 1.96 \\
\hline & Exotic & 94 & 92.16 \\
\hline & Both & 6 & 5.88 \\
\hline \multirow{3}{*}{$\begin{array}{l}\text { Breeding } \\
\text { practice }\end{array}$} & Natural(bull) & 5 & 4.90 \\
\hline & $\begin{array}{c}\text { Artificial } \\
\text { insemination }\end{array}$ & 76 & 74.51 \\
\hline & Both & 21 & 20.59 \\
\hline
\end{tabular}

\section{Respondents' Awareness Level and Management \\ Practices}

The majority of the respondents interviewed (94.12\%) were found to know that animals kept for dairy purposes should be given a mix of animal feeds containing different feed staffs that belong to the class of roughages and concentrate. However, (43.14\%) of the respondents have either failed to explain any of the recommended scientific ration formulations or have given an irregular proportion, and in most of the cases feed formulation was mainly done on personal or individual worker's experience. According to heath management, most respondent use (97.06) regular veterinary consultancy. In the study area most of the respondents' use (68.63) tap water was as a source of water for their dairy cow whereas $(31.37 \%)$ of respondents indicated that the sources of water for their animals were stagnant). Regarding the frequency of watering of their cattle, most of their animals got water twice a day as indicated by (56.86\%) of the respondents (Table 3 ). 
Table 3: Respondents' awareness level and farm management practices in selected dairy farms in and around Wolaita Sodo $(\mathrm{n}=$ 102).

\begin{tabular}{|c|c|c|c|}
\hline Variables & Category & $\begin{array}{l}\text { Frequency } \\
\text { (N) }\end{array}$ & $\begin{array}{c}\text { Percentage } \\
(\%)\end{array}$ \\
\hline \multirow{3}{*}{ Feed type used } & Roughages only & 6 & 5.88 \\
\hline & Concentrates only & 0 & 0 \\
\hline & Mix of both & 96 & 94.12 \\
\hline \multirow{4}{*}{ Feeding } & Once & 5 & 4.90 \\
\hline & Twice & 61 & 59.80 \\
\hline & Trice & 18 & 17.65 \\
\hline & Ad libitum & 18 & 17.65 \\
\hline \multirow{2}{*}{$\begin{array}{l}\text { Practice ration } \\
\text { formulation }\end{array}$} & Yes & 58 & 56.86 \\
\hline & No/not acceptable & 44 & 43.14 \\
\hline \multirow{3}{*}{$\begin{array}{c}\text { Health } \\
\text { Management }\end{array}$} & $\begin{array}{l}\text { Regular Veterinarian } \\
\text { consultancy }\end{array}$ & 99 & 97.06 \\
\hline & Deworming only & 2 & 1.96 \\
\hline & No follow-ups & 1 & 0.98 \\
\hline \multirow{3}{*}{ Watering } & Once & 19 & 18.63 \\
\hline & Twice & 58 & 56.86 \\
\hline & Ad-libitum & 25 & 24.51 \\
\hline \multirow{2}{*}{$\begin{array}{l}\text { Watering } \\
\text { system }\end{array}$} & Tap water & 70 & 68.63 \\
\hline & Stagnant water & 32 & 31.37 \\
\hline
\end{tabular}

According to the response of respondents, the challenges decreasing production and productivity of the dairy sector are a limitation of healthcare service, feed shortage, financial problems; market-related problems, multiple responses, and diseases (Table 4). Feed shortage was the main problem especially during a dry season (58.82\%) in dairy farms. The next present finding challenges encountered in the dairy sector was disease as shown by (20.59\%) of the respondents while multiple responses and market problems were $(11.76 \%, 3.92 \%)$ of the interviewee respectively.

\section{Farm Challenges and Major Health Problems}

As shown in the Figure 2, there were different challenges in the study sites. Among these, dry season (58.82\%), feed shortage and wet season $(41.18 \%)$ were the most common challenges seen in the study sites. Regarding respondents, the major health problems reported in the dairy farm owner in the current study area were infectious diseases, parasitic, metabolic and reproductive, and other diseases and disorders as stated (Table 5).

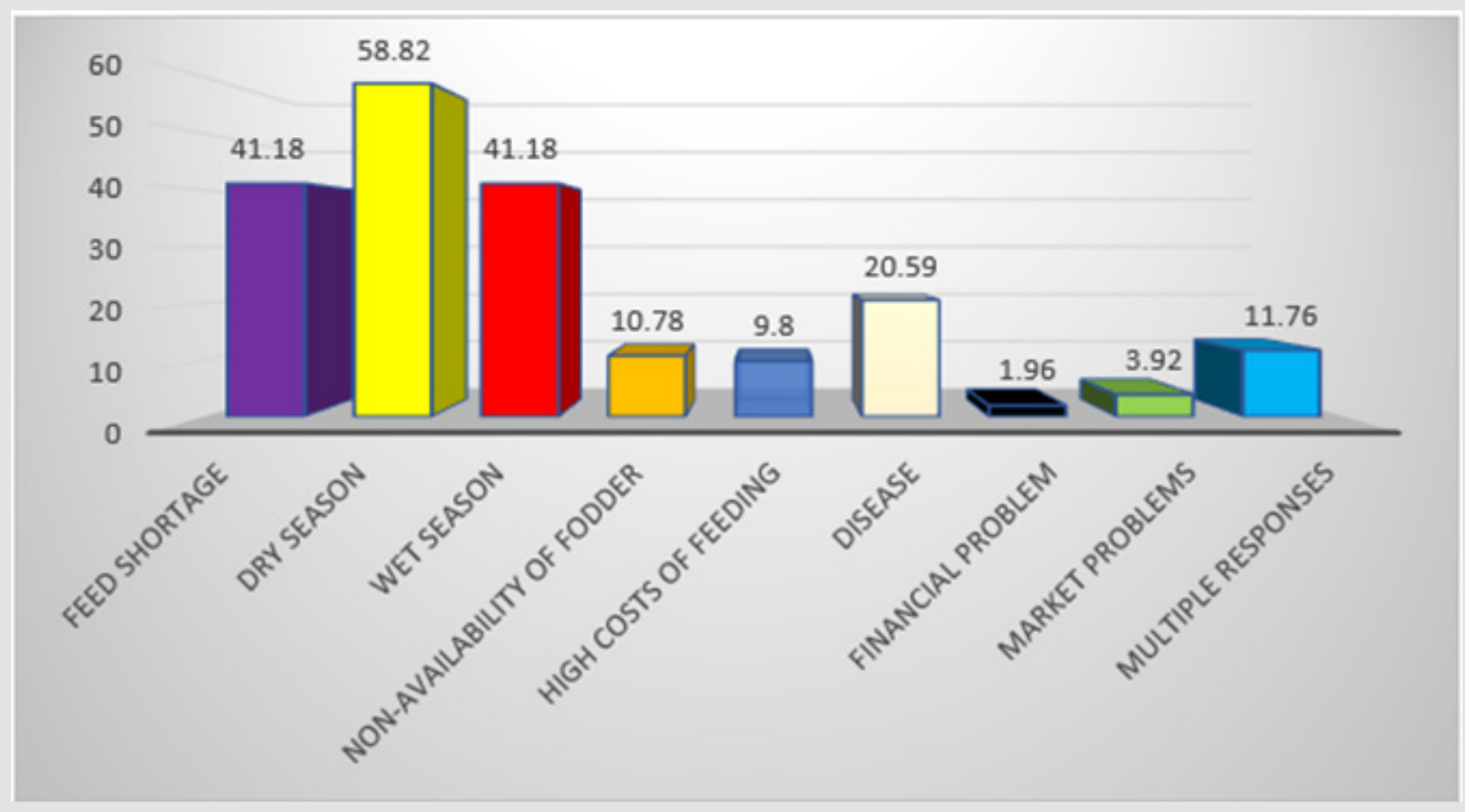

Figure 2: Major farm challenges faced and reported as well as routinely examined health problems of dairy cows in selected dairy farms.. 
Table 5: Major reported and observed health problem in dairy farms of the study area.

\begin{tabular}{|c|c|c|c|}
\hline Variables & Category & Frequency $(\mathrm{N})$ & Percentage (\%) \\
\hline \multirow{22}{*}{ Reported health problems } & \multicolumn{3}{|c|}{ Parasitic diseases } \\
\hline & Trypanosomiasis & 16 & 15.69 \\
\hline & Tick infestation & 32 & 31.37 \\
\hline & Mange mite & 2 & 1.96 \\
\hline & GIT parasite & 16 & 15.69 \\
\hline & \multicolumn{3}{|c|}{ Infectious disease } \\
\hline & Actinomycosis and Actinobacillosis & 19 & 18.63 \\
\hline & LSD & 10 & 9.80 \\
\hline & Blackleg & 11 & 10.78 \\
\hline & Pasteurellosis & 41 & 40.20 \\
\hline & \multicolumn{3}{|c|}{ Metabolic andreproductive problems } \\
\hline & Hypocalcemia & 16 & 15.69 \\
\hline & Bloat & 24 & 23.53 \\
\hline & Mastitis & 42 & 41.18 \\
\hline & Retained placenta & 25 & 24.51 \\
\hline & Dystocia & 12 & 11.76 \\
\hline & Repeat breeding and anestrous & 52 & 50.98 \\
\hline & \multicolumn{3}{|c|}{ Other diseases and disorder } \\
\hline & Calf diarrhea & 5 & 4.90 \\
\hline & Lameness & 7 & 6.86 \\
\hline & Pneumonia & 4 & 3.92 \\
\hline & Wound problem & 7 & 6.86 \\
\hline \multirow{6}{*}{ Observed/examined health problems } & Tick infestation & 5 & 4.90 \\
\hline & Hoof overgrowth & 20 & 19.60 \\
\hline & Mastitis & 1 & 0.98 \\
\hline & Lameness & 1 & 0.98 \\
\hline & Wound problems & 1 & 0.98 \\
\hline & Uterine prolapse & 1 & 0.98 \\
\hline
\end{tabular}

\section{Associations among Variables and Risk Factors}

Most of the dairy farm owners and workers (39.4\%) carried out their work through longer experiences of $>10$ years. However, no significant association $(\mathrm{P}>0.05)$ was found between the type of feed used and respondents' work experience (Table 6). Likewise, there was also no statistically significant association $(\mathrm{P}>0.05)$ between the farm management practices and respondents' educational levels (Table 7).

Table 6: Association of some of the selected dairy farm management practices against the working experience of respondents.

\begin{tabular}{|c|c|c|c|c|c|c|}
\hline \multirow{2}{*}{$\begin{array}{c}\text { Farm Management } \\
\text { Practices }\end{array}$} & \multirow{2}{*}{ Category } & \multicolumn{3}{|c|}{ Respondents Working Experience (years) n (\%) } & \multirow{2}{*}{ Chi-square $\left(\mathrm{X}^{2}\right)$} & \multirow{2}{*}{ p-value } \\
\hline & & $<5$ & $5-10$ & $>10$ & & \\
\hline \multirow{3}{*}{ Health management } & Vet. Consultancy & $29(29.3)$ & $39(39.4)$ & $31(31.3)$ & \multirow{3}{*}{2.3673} & \multirow{3}{*}{0.669} \\
\hline & Deworming only & $0(0)$ & $1(50)$ & $1(50)$ & & \\
\hline & No follow-up & $0(0)$ & $1(100)$ & $0(0)$ & & \\
\hline \multirow{3}{*}{ Management system } & Intensive & $15(22.06)$ & $30(44.12)$ & $23(33.82)$ & \multirow{3}{*}{5.8372} & \multirow{3}{*}{0.212} \\
\hline & Semi-intensive & $13(39.4)$ & $11(33.3)$ & $9(27.3)$ & & \\
\hline & Extensive & $1(100)$ & $0(0)$ & $0(0)$ & & \\
\hline \multirow{2}{*}{ Feed type } & Roughage & $3(50)$ & $2(33.3)$ & $1(16.7)$ & \multirow{2}{*}{1.5573} & \multirow{2}{*}{0.459} \\
\hline & Mixed & $26(27.08)$ & $39(40.63)$ & 31 (32.29) & & \\
\hline
\end{tabular}




\begin{tabular}{|c|c|c|c|c|c|}
\hline \multirow{4}{*}{ Feeding frequency/day } & Once & $1(20)$ & $3(60)$ & $1(20)$ & \multirow{4}{*}{5.0152} \\
\cline { 2 - 4 } & Twice & $17(27.87)$ & $25(40.98)$ & $19(31.15)$ & \multirow{2}{*}{0.542} \\
\cline { 2 - 5 } & Thrice & $3(16.67)$ & $7(38.89)$ & $8(44.44)$ & \\
\cline { 2 - 4 } & Daily & $8(44.44)$ & $6(33.33)$ & $4(22.22)$ & \\
\hline
\end{tabular}

Table 7: Association of the selected dairy farm management practices against the educational level of respondents.

\begin{tabular}{|c|c|c|c|c|c|c|c|}
\hline \multirow{2}{*}{$\begin{array}{c}\text { Farm Management } \\
\text { Practices }\end{array}$} & \multirow{2}{*}{ Category } & \multicolumn{4}{|c|}{ Respondents' Educational Level (\%) } & \multirow{2}{*}{ Chi-square $\left(X^{2}\right)$} & \multirow{2}{*}{ p-value } \\
\hline & & None formal & Elementary & High school & Diploma & & \\
\hline \multirow{3}{*}{ Health management } & Vet. Consultancy & $\begin{array}{c}15 \\
(15.15)\end{array}$ & $\begin{array}{c}24 \\
(24.24)\end{array}$ & $\begin{array}{c}28 \\
(28.28)\end{array}$ & $\begin{array}{c}32 \\
(32.32)\end{array}$ & \multirow{3}{*}{5.0773} & \multirow{3}{*}{0.534} \\
\hline & Deworming only & $1(50)$ & $0(0)$ & $1(50)$ & $0(0)$ & & \\
\hline & No follow-up & $0(0)$ & $0(0)$ & $0(0)$ & $1(100)$ & & \\
\hline \multirow{3}{*}{ Management system } & Intensive & $\begin{array}{c}9 \\
(13.24)\end{array}$ & $\begin{array}{c}13 \\
(19.12)\end{array}$ & $\begin{array}{c}22 \\
(32.35) \\
\end{array}$ & $\begin{array}{c}24 \\
(35.29)\end{array}$ & \multirow{3}{*}{6.7766} & \multirow{3}{*}{0.342} \\
\hline & Semi-intensive & $\begin{array}{c}7 \\
(21.21) \\
\end{array}$ & $\begin{array}{c}10 \\
(30.3) \\
\end{array}$ & $\begin{array}{c}7 \\
(21.21) \\
\end{array}$ & $\begin{array}{c}9 \\
(27.27) \\
\end{array}$ & & \\
\hline & Extensive & $0(0)$ & $1(100)$ & $0(0)$ & $0(0)$ & & \\
\hline \multirow{2}{*}{ Feed type } & Roughage & $\begin{array}{c}1 \\
(16.67)\end{array}$ & $\begin{array}{c}2 \\
(33.33)\end{array}$ & $\begin{array}{c}1 \\
(16.67)\end{array}$ & $\begin{array}{c}2 \\
(33.33)\end{array}$ & \multirow{2}{*}{0.5766} & \multirow{2}{*}{0.902} \\
\hline & Mixed & $\begin{array}{c}15 \\
(15.63) \\
\end{array}$ & $\begin{array}{c}22 \\
(22.92) \\
\end{array}$ & $\begin{array}{c}28 \\
(29.17) \\
\end{array}$ & $\begin{array}{c}31 \\
(32.29) \\
\end{array}$ & & \\
\hline \multirow{4}{*}{$\begin{array}{l}\text { Feeding frequency/ } \\
\text { day }\end{array}$} & Once & $\begin{array}{c}2 \\
(40) \\
\end{array}$ & $\begin{array}{c}2 \\
(40 \\
\end{array}$ & $\begin{array}{c}1 \\
(20 \\
\end{array}$ & $0(0)$ & \multirow{4}{*}{13.1436} & \multirow{4}{*}{0.156} \\
\hline & Twice & $\begin{array}{c}9 \\
(14.75) \\
\end{array}$ & $\begin{array}{c}12 \\
(19.67) \\
\end{array}$ & $\begin{array}{c}14 \\
(22.95 \\
\end{array}$ & $\begin{array}{c}26 \\
(42.62) \\
\end{array}$ & & \\
\hline & Thrice & $\begin{array}{c}2 \\
(11.11) \\
\end{array}$ & $\begin{array}{c}4 \\
(22.22) \\
\end{array}$ & $\begin{array}{c}9 \\
(50 \\
\end{array}$ & $\begin{array}{c}3 \\
(16.67) \\
\end{array}$ & & \\
\hline & Daily & $\begin{array}{c}3 \\
(16.67)\end{array}$ & $\begin{array}{c}6 \\
(33.33)\end{array}$ & $\begin{array}{c}5 \\
(27.78)\end{array}$ & $\begin{array}{c}4 \\
(22.22)\end{array}$ & & \\
\hline
\end{tabular}

\section{Treatment and Control Measures}

During the current assessment on the major management practice option for the various animal challenges encountered in the dairy farms were also assessed, for the treatment option and a preventive measure the majority of the farms respondent was using modern treatment as explained by (86.27\%) whereas both indicated that $(13.73 \%)$ they were using both modern and traditional treatment (Table 8). At the same time, most of the dairy farm respondents $(88.24 \%)$ were explained that the practice of vaccination to control the occurrence of diseases was done by the health technicians employed in the areas (Table 9).
Table 8: Measures were taken of treatment option and a preventive measure of response with their respective proportion

\begin{tabular}{|c|c|c|}
\hline Treatment option & Frequency (N) & Percentage (\%) \\
\hline Modern treatment & 88 & 86.27 \\
\hline Traditional treatment & 0 & 0.0 \\
\hline Both & 14 & 13.73 \\
\hline \multicolumn{2}{|c|}{ Preventive measure } \\
\hline Vaccination & 90 & 88.24 \\
\hline Slaughter & 0 & 0.0 \\
\hline Quarantine & 0 & 0.0 \\
\hline Do nothing & 12 & 11.76 \\
\hline
\end{tabular}


Table 9: Vaccination types, dosage, route, time/season, and frequency.

\begin{tabular}{|c|c|c|c|c|c|c|}
\hline No. & Vaccine type & Dosage & Route & Season & Regularity & Frequency (\%) \\
\hline 1 & Anthrax & $1 \mathrm{ml}$ & S/c & September to October & Yearly & $2(1.96)$ \\
\hline 2 & Blackleg & $2 \mathrm{ml}$ & S/c & September to October & Twice a year & $35(34.31)$ \\
\hline 3 & LSD & $1 \mathrm{ml}$ & S/c & January & Yearly & $17(16.67)$ \\
\hline 4 & CBPP & $1 \mathrm{ml}$ & S/c & January & Yearly & $1(0.98)$ \\
\hline 5 & Bovine pasteurellosis & $2 \mathrm{ml}$ & S/c & November & Yearly & $21(20.59)$ \\
\hline 6 & $\begin{array}{c}\text { LSD and bovine } \\
\text { pasteurellosis }\end{array}$ & - & S/c & - & Twice \& Yearly & $1(0.98)$ \\
\hline 7 & LSD and Blackleg & - & S/c & - & Yearly & $8(7.84)$ \\
\hline 8 & Other & - & S/c & - & Yearly & $3(1.96)$ \\
\hline 9 & All & - & S/c & - & & $3(2.94)$ \\
\hline
\end{tabular}

\section{Results of Observational Study}

a) Feeding and Watering Management: By the observational study the commonly used and frequently applied feedstuffs in the medium and large-scale dairy farms include straw, grass hay, and concentrate" Fruska". But in the small scale $(<5)$ dairy farms straw, grass hay, concentrate" Fruska and house left materials (such as coffee and avocado leftovers) mainly present. In most dairy farms, salt supplementation is done on straw and grass hay to increase palatability. The duration and frequency of feeding and feed types are given for the animals mainly depend on the age type and lactation. The frequency of concentrate feeding is done twice a day in the morning and afternoon. Watering is also practiced twice a day but given as required too. Tap and stagnant water are the two sources that are used in the study area but most dairy farm owners in the Sodo town used tape water which is given manually or in watering troughs.

b) Housing: From the 102 dairy farms, in Sodo (84.31\%) and lesser in Sodo zuriya (15.69\%). In the small-scale dairy farms, the barns do not have partitions, both calves and cows are placed in the same place which leads to the occurrence of disease. But in the medium and large-scale dairy farms, there is a partition class in which the animals are grouped based on their age, lactation, and pregnancy stages. The materials used for the construction of the barns were the roof and wall were made of metallic sheet /tin, cement, and concrete in the Sodo dairy farms whereas in the Sodo zuriya areas were made of tin/grass, soil, and wood.

\section{c) Hygienic practice}

Many dairy farm owners have awareness level on the hygienic practice mainly on the washing of udder during and after milking by omo and clean water and they dry it by the towel. Additional dairy farm owners wash their animal bodies by water when they dirty with dung.

d) Major health problems: During the study area, the major health problems that observed were parasitic diseases (tick infestation, 4.90\%), Hoof overgrowth (19.60\%), reproductive problem (Mastitis, 0.98\% and Uterine prolapse, 0.98\%) and other disorder (Lameness, $0.98 \%$ and Wound problems, $0.98 \%$ ) observed based on tentative diagnosis (Table 5). Treatment, vaccination, and control measures: Treatment and vaccination were done by the health technicians employed in the areas. Diagnosis of disease was mainly done tentatively because of a lack of veterinary laboratory equipment and reagents in the study area. Besides, the farmers were observed to use modern drugs after consulting a veterinarian. Although there is a lack of veterinary professionals, traditional treatment is less practiced

\section{Discussion}

Nowadays dairy cattle farming is becoming an emerging business sector in most of the developing countries, including Ethiopia. This sector supports the economy and home consumption of the wider community. As part of the country's growth and development, livestock breeding and intensification were the priority areas of the governmental and private sectors in the country (MOA, 2014). But, a lot of remains to be done in improving constraints and major health problems of dairy farms, as well as the general husbandry and management practice of dairy farms that primarily related to the worker's knowledge and practical skills in this study, is contributed towards that. In the current study, showed that the majority of visited dairy farms were $(81.37 \%)$ private owned, (17.65\%) cooperative, and $(0.98 \%)$ government with a majority of them were having closed housing types (50.98\%).

Moreover, Dewier [14] has also added that animals kept in nonconfined open-air houses can easily express their natural physiological behaviors and their welfare being considered too which will have a positive effect on their overall productivity. With respect to the dairy farm type/scale, the majority of the study farms $(44.12 \%)$ were small scale dairy farms with less than 5 heads of dairy cows, followed by (31.37\%) medium scale with 5-10 heads, and the rest $(24.51 \%)$ having more than 10 heads regarded as large-scale farms. In line with these findings, it was stated that a small scale $(<5)$, medium-scale (5-10), and large scale $(>10)$ heads of dairy cows respectively [13]. The majority of the dairy farm 
respondents (52.94\%) were males and (47.06\%) were females with 5-10 years of dairy farm work experiences (40.20\%). Regarding the educational background of the dairy farm workers, the current finding showed that $(15.69 \%, 23.53 \%, 28.43 \%$, and $32.35 \%)$ of the workers were attended none formal education, Elementary school, High school and Diploma/above respectively. The educational levels of the dairy farm owners and workers have diploma/above $(32.35 \%)$ which is highly important for general management and husbandry practices in the dairy farm when compared to that of the rest educational respondents.

Therefore, the educational levels of the dairy farm owners and work experience have an impact on general constrains improvement and management practice and other health problems. However, this finding is not in line with the report of Daniel [15] who has documented that only $12 \%$ of respondents enrolled in primary schools and $2.7 \%$ attend secondary school. This difference seems to arise from the differences in awareness and access to education. The majority of observed dairy farms (89.22\%) were to rear Young and adult dairy cows in their farms. Similarly, Felleke and Geda, [16] have stated that young cows or heifers need to be raised in a dairy farm investment as replacement stock for the future sustainability of the farm. Furthermore, results have also indicated that most of the dairy farm respondents were aware of the management of their animals' health through regular veterinary consultancy $(97.06 \%)$ and deworming (1.96\%). In agreement with this finding, Abebe et al., [17] have stated that animal health management through veterinary consultancy and deworming are important measures that increase the productivity of animals in a generally good performance.

According to the current study (94.12\%), most of the assessed dairy farm respondents were using a mixed feed, both the concentrates and roughages. Most dairy farm respondents (56.86\%) awareness on the feed formulation with its contents but (43.14\%) were found not to practice or to use an irregular ration formulation. Similarly, Solomon, [18] has also reported that animals cannot be expected to produce at their greatest potential unless they are properly fed with a balanced ration of protein, carbohydrate, fats, minerals, vitamins, and water. It was so far stated that dairy farm owners should use the recommended standards, feed composition tables, and also must understand the daily requirement of the animal for maintenance and production to properly design a balanced ration [19]. During the assessment, (68.63\%) of respondents indicated that the source of water is tap water where us $(31.37 \%)$ of the respondents indicated that the source of water stagnant. The majority (56.86\%) of the respondents indicated that their cattle are getting water twice per day whereas (18.63\%) and $(24.51 \%)$ of them stated that water was given to their cattle once per day and Ad-libitum (required too) respectively. This finding is in agreement with that of Birhanu et al. [20].
This study revealed that Feed shortage and disease was the most important constraints of dairy production in the study area. The present study was comparable with the findings of Bishu et al. [21] who reported that the availability and costs of feeds, diseases, and low veterinary service were noted as major constraints in Hosanna town, Ethiopia. The respondents said that diseases (20.59\%) were impacting dairy production in many ways such as reduced body weight, growth rate, low milk production, and reproductive performance, mortality and high treatment cost and this agree with Perry [19] and Tefera [22] who reported that poorly fed animals develop low disease resistance because the animal health care system relies heavily on veterinary measures and management systems similar to the finding of Girma [23].

In the current study area show that feeding shortage (41.18\%) was a major problem in dry season although (58.82\%). In the wet seasons, the dairy farm owner readily gets their feed from government offices, schools, religious areas, and private land. At the same time, the present finding showed that the non-availability of fodder around the year, high costs of feeding, market problems, multiple problems, and financial problems were some of the challenges encountered in the dairy sector within the study area. The current result showed that major health challenges that were reported including a parasite, infectious, metabolic and reproductive and other diseases/disordered followed by feed shortage and poor housing management of the dairy cattle were encountered frequently in the study area. Finally, results of the observational study have shown that tick infestations (4.90\%), reproductive problems (both mastitis and uterine prolapse, 0.98\%) and other diseases/disorder (Hoof overgrowth, 19.60\%, lameness, 0.98 and wound problem, $0.98 \%$ ) were the major health problems noticed in the study dairy farms. In agreement with these findings, Nwaru et al., [24] reported that livestock diseases are the principal factors affecting the production and productivity of dairy plants. Moreover, Dawit and Ahmed, [25] reported several reproductive health problems including lameness, sterility, dystocia, and brucellosis, in dairy cows kept under different management systems in and around Kombolcha, Northern-Ethiopia [26-37].

\section{Conclusion and Recommendation}

According to the present findings study, dairy production was an important enterprise, investment and has the potential to be economically viable and greatly contribute to food security, improved family nutrition, and income and employment generation in Sodo and Sodo zuriya. However, feed shortages, as well as the high cost of feed, the occurrence of disease, financial and marketing problems, were the main constraints limiting dairy production in the study area. most of the dairy farm respondents were used a mixed feed. This is important to balance the feedstuff used to satisfy the animal's requirement. The respondents' ability to list down some of the challenges faced by a dairy farm and state the 
health problems and management procedures they use to follow was relatively better. The health problems, management problems, and diseases control measures were found in the current study were generally better.

Therefore, based on the above conclusion the following recommendations are forwarded

a) Dairy farm owner and workers should have to get regular training programs on dairy farm management and strategic control measures of diseases

b) Regular health management and proper feed formulation ration mandatory to reduce the problem encountered in different production systems of the dairy farms.

c) Further research should be done on the constrains of dairy cattle so that proper control and preventive measures will be devised.

\section{References}

1. Thornton P K (2010) Livestock production: recent trends, future prospects. The Royal Society 365: 2853-2867.

2. CSA (2012) Ethiopia demographic and health survey 2011. Addis Ababa Ethiopia and Calverton Maryland USA: Central Statistical Agency and ICF International 5: 430-498.

3. Stoltenow C L, Vincent L L (2003) Proceedings of the 5th national conference, the Ethiopian society of animal production (ESAP) Ethiopia 28-39.

4. (2004) The state of Ethiopians Farmer animal genetic resource country report. A contribution to the first report on the state of the World's Animal Genetic Resources.

5. Njombe AP, Msanga Y, Mbwambo N, Makembe N (2011) The Tanzania Dairy Industry: Status, Opportunities and Prospects, Ministry of Livestock and Fisheries Development. African Dairy Conference and Exhibition, Dar es Salaam, Tanzania.

6. Zelalem Y, Emannuelle GB, Ameha S (2011) A Review of the Ethiopian Dairy Sector. Food and Agriculture Organization of the United Nations Ethiopia.

7. (2013) CSA (Central Statistical Agency),Agricultural sample survey. Report on livestock and livestock characteristics. The Federal Democratic Republic of Ethiopia Private Peasant Holdings.

8. (2006) DACA, Standard veterinary treatment guidelines for veterinary. Practice 1 ed 3-13.

9. Assefa A (2005) From management in the mixed crop-livestock production system in the northern highland of Ethiopia. 34 .

10. Lobago F, Bekana M, Gustafson H, Kindahl H (2006) Reproductive performance of dairy cows in smallholder production systems in Sellable, Central Ethiopia. Tropical Animal Health and Production 38: 333-342.

11. Shitaye J E, W Tsegaye, I Paulik (2007) Bovine tuberculosis infection in animal and human populations in Ethiopia. Veterinary Medicine 52(8): 317-332.

12. (2011) WZFEDD Wolaita Zone Financial and Economic Development Department. Zonal Basic Socio-economic and Demographic Information.

13. (2007) ILRI ILRI annual report 2007: markets that work making a living from livestock. 55-67.
14. Dewier J L (2008) The speech-language pathologist's role in the Neonatal Intensive Care Unit. Research Papers 40: 16-19.

15. Daniel T (2008) Beef and Dairy Cattle Production Systems and Opportunities for Market Orientation in Borena Zone Southern Ethiopia. MSc Thesis 23-25.

16. Felleke G, G Geda (2001) The Ethiopian dairy development policy: A draft policy document Ministry of Agriculture/AFRDRD/AFRDT Food and agriculture Organization/SSFF. Addis Ababa Ethiopia 9: 333-342.

17. Abebe W, Mekonnen H, Moges W, Getachew T (2001) Effect of Concentrate Supplementation and Deworming on Beef Performance of Indigenous Ethiopian Zebu Cattle Fed on Teff Straw. Faculty of Veterinary Medicine 152(4): 307-310.

18. Solomon B (2004) Assessments of livestock production systems and feed resources. 141-143.

19. Perry T W (1993) Beef cattle feeding. The daily animals requirement for maintenance and production. Academic Press 6: 234-241.

20. Berhanu W, D Colman, B Fayissa (2007) Diversification and livelihood sustainability in a semi-arid environment: A case study from southern Ethiopia. The Journal of Development Studies 43: 871-889.

21. Bishu K G, S O Reilly, E Lahiff, B Steiner (2016) Cattle farmers' perceptions of risk and risk management strategies: evidence from Northern Ethiopia. Journal of Risk Research 21(5): 579-598.

22. Tefera E (2008) The Role of Dairy Cooperatives in Stimulating Innovation and Market Oriented Smallholders Development: The Case of Ada's Dairy Cooperative, Central Ethiopia. Haramaya University 2839.

23. Girma A (2008) Dairy Service Delivery in DebreZeit Milkshed of Ada'a District, Central Ethiopia: Analyzing Options to Development Pluralistic Service Delivery in the Dairy Sector. MSc Pluralistic Service Delivery in the Dairy Sector 581-593.

24. Nwaru J, Onyenweaku C, Nwosu A (2006) Relative Technical Efficiency of Credit and Non Credit User Crop Farmers. Products and Productivity, African Crop Science Journal 14(3): 241-251.

25. Dawite T, Ahmed S (2013) Reproductive health problems of cows under different management systems in Kombolcha, Northeast Ethiopia. Advances in Biological Research 7(3): 104108.

26. Amaha K, Etsay K, Maleku T (2002) An Integrated Urban, Peri-Urban and Rural Dairy Development Program in Tigray. Dairy animal health project $12-32$.

27. Anon (2009) Export products of Ethiopia in all regions.

28. Delgado CL (2003) Rising consumption of meat and milk in developing countries has created a new food revolution. J Nutr 133(11 Suppl 2): 3907S-3910S.

29. Ferguson J, Galligan D (2000) Assessment of reproductive efficiency in dairy herds. Compend Contin Ed Prac Vet 22(11): 159- 158.

30. Getachew E (2002) Assessment of feed resources, their management, and the impact on livestock production. Addis Ababa University College of Veterinary Medicine Ethiopia 111-124.

31. Ndambi A, Hemme U, Latacz L (2007) Dairying in Africa: Status and recent developments. Livestock Research for Rural Development 19(111): 234-242.

32. Noordhuizen J (2012) Dairy Herd Health and management, A guide for veterinarians and dairy professionals, Mill Street Packington UK.

33. Plazier J, King G, Dekkers C, Lissemore K (2002) Estimation of economic values of indices for reproductive performance in dairy herds using computer simulation. J Dairy sci 80(11): 2775-2783.

34. Tadesse Guadu, Mengistie Abebaw (2016) Challenges, Opportunities, and Prospects of Dairy Farming in Ethiopia: A Review. World Journal of Dairy and Food Sciences 11(1): 01-09. 
35. Tegegne A, Gebrewold A (1998) Prospects for peri-urban dairy development in Ethiopia. 28-39.

36. Tessema Z (2003) Assessment of livestock production systems and available feed resources, and marketing situation. Addis Ababa Ethiopia pp. 407-418.

\section{ISSN: 2574-1241}

DOI: $10.26717 /$ BJSTR.2020.30.004904

Haben Fesseha. Biomed J Sci \& Tech Res

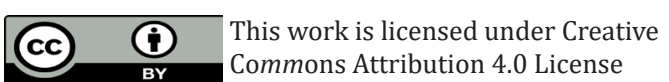

Submission Link: https://biomedres.us/submit-manuscript.php
37. Wudu T, Kelay B, Mekonen H, Tesfu K (2008) Calf morbidity and mortality in smallholder dairy farms in Adealiben districts of Oromia region Ethiopia. Tropical Animal Health and production 40(5): 369376 .

\begin{tabular}{ll} 
BIOMEDICAL & Assets of Publishing with us \\
RESEARCHES & - Global archiving of articles \\
& - Immediate, unrestricted online access \\
\hline
\end{tabular}

